\title{
História indígena, antropologia e fontes orais: questões teóricas e metodológicas no diálogo com o tempo presente
}

\author{
Joana Aparecida Fernandes Silva* \\ Giovani José da Silva**
}

\section{Considerações iniciais}

Os trabalhos com fontes orais relacionados a populações indígenas, no âmbito da história, ainda são escassos no Brasil. Verificando-se anais e cadernos de resumos dos últimos quatro Encontros Nacionais de História Oral, realizados, respectivamente, em São Paulo (2002), Goiânia (2004), Rio Branco (2006) e São Leopoldo (RS) (2008), percebe-se que apenas no último o número de trabalhos envolvendo a temática cresceu consideravelmente. ${ }^{1}$ Naquela ocasião, seis trabalhos, versando sobre populações indígenas (chiquitano, guarani-kaiowá, guarani-mbyá, guarani-ñandeva, kamba, terena e xucuru) foram divulgados. Já nos três encontros anteriores, haviam sido apresentados, em conjunto, apenas sete trabalhos, tratando de distintas etnias:

* Doutora em Antropologia e docente da Universidade Federal de Goiás (UFG).

** Doutor em História e docente da Universidade Federal de Mato Grosso do Sul (UFMS)/Campus de Nova Andradina.

1 Para o breve levantamento aqui pretendido, recorreu-se aos Anais, editados em CD-ROM, do VI Encontro Nacional de História Oral (São Paulo, 2002), do VII Encontro Nacional de História Oral (Goiânia, 2004) e aos Cadernos de resumos do VIII Encontro Nacional de História Oral (Rio Branco, 2006) e do IX Encontro Nacional de História Oral (São Leopoldo, 2008). Ressalta-se que não foram contabilizados os poucos artigos que trataram as questôes indígenas de forma genérica, sem nomear grupos em seus títulos ou mesmo nos resumos (ver, por exemplo, Silva; José da Silva, 2006; Tenedini, 2008; Von Simson, 2008). 
macuxi e karajá (em Goiânia); krahô e apinajé (no encontro de São Paulo); yawanawa, manchinen, apurinã, jaminawa, kaxinawá, shanenawa, poyanawa, kapinawá, pipipan (em Rio Branco). Dessa forma, é possível afirmar haver uma tendência de crescimento tanto quantitativo como qualitativo em relação às pesquisas produzidas no país e que envolvem a temática. ${ }^{2}$

História Oral, importante periódico editado pela ABHO (Associação Brasileira de História Oral) - entidade promotora dos encontros nacionais -, publicou, em 13 edições (até dezembro de 2007), três trabalhos sobre a utilização de fontes orais relacionados ao estudo de populações indígenas. No artigo "Yalanewitisu: o espaço nambiquara da memória", Anna Maria Ribeiro Fernandes Moreira da Costa (2005) analisa a forma como os fatos do tempo pretérito são articulados entre os Nambikuara, da Chapada dos Parecis, em Mato Grosso. Em "Fala de índio, História do Brasil: o desafio da Etno-História Indígena”, Edinaldo Bezerra de Freitas (2004) aborda, através de uma experiência entre os Krahô, no estado de Tocantins, a utilização de fontes orais com populações indígenas, contribuindo para as discussões sobre uso e transformação de narrativas indígenas e das oralidades em conhecimento histórico. ${ }^{3}$ Além desses artigos, produzidos por historiadores, há, ainda, o trabalho intitulado "Os Tembé e a relação pesquisador-pesquisado", de autoria da antropóloga Sara Alonso (2001).

Por que ainda poucos trabalhos abordam uma temática tão rica, complexa e instigante? Longe de se chegar a uma resposta definitiva a essa pergunta, o presente artigo pretende abordar aspectos teóricos e metodológicos relacionados ao trabalho de historiadores e antropólogos com as fontes orais. Alguma confusão se verifica quando o assunto é a oralidade, especialmente nas pesquisas realizadas entre populações indígenas. Espera-se mostrar que, apesar de semelhanças, há também diferenças que delimitam e configuram as áreas de atuação dos pesquisadores da história e da antropologia, e não se pode confundir o que cada grupo, com propósitos diversificados (e, algumas vezes, convergentes), realiza ao investigar populações indígenas, utilizandose de fontes orais.

2 Ver Freitas (2002), Giraldin (2002), Portela (2004), Miranda (2004), Litwinczik (2006), Lopes (2006), Machado e Montenegro (2006), Almeida (2008), Hofmann (2008), José da Silva (2008), Maciel (2008), Puhl (2008) e Silva (2008).

3 Trata-se do mesmo texto, com poucas alterações, apresentado pelo autor no VI Encontro Nacional de História Oral, em São Paulo (2002). 


\section{História indígena e fontes orais}

Se no Brasil ainda é escassa a divulgação dos trabalhos envolvendo populações indígenas e fontes orais, o mesmo não ocorre em outros países das Américas, tais como a Bolívia (ver Hagen, 1992 e Riester, 1994, por exemplo). Pode-se dizer que múltiplos são os desafios para os pesquisadores que se aventuram a estudar história indígena no Brasil.

Nesse sentido, as palavras de John Manuel Monteiro (1995, p. 221) aparentemente ainda fazem sentido no meio acadêmico do país:

A historiografia brasileira, ao longo das últimas décadas, tem buscado incorporar grupos sociais antes ignorados pela bibliografia. Ao mesmo tempo, abordagens antropológicas têm penetrado diversas áreas de investigação histórica, abrangendo estudos sobre a inquisição, a escravidão, as relações de gênero, as mentalidades, entre tantos outros assuntos. Diante deste quadro, contudo, é de se estranhar a pouca atenção dispensada aos povos indígenas pelos historiadores.

Mais de uma década se passou desde a publicação do texto "O desafio da história indígena no Brasil”, do qual foi extraído o trecho citado acima. Entretanto, especialmente na década de 1990, a abertura de inúmeros cursos de pós-graduação em história pelo interior do país provocou algumas mudanças na situação geral da pesquisa histórica com populações indígenas. Isso porque os estudos de história regional receberam significativas contribuições por meio de trabalhos universitários produzidos ao longo dos últimos anos. Além disso, as transformações recentes da história brasileira chamaram a atenção para regiões até então pouco estudadas, tais como o Norte e o Centro-Oeste.

De acordo com Janaína Amado (1990), esses estudos receberam grande impulso no meio acadêmico brasileiro, devido a inúmeros fatores: a mudança do conceito de "região", o esgotamento das "macroabordagens" e das grandes sínteses, a instalação e o desenvolvimento de cursos de pós-graduação no país. Dentre esses cursos, podem ser destacados o Programa de Pós-Graduação em História da Universidade Federal de Goiás (UFG), em atividade desde o início dos anos 1970, além dos programas das Universidades Federais de Mato Grosso (UFMT) e de Mato Grosso do Sul (UFMS), ambos iniciados no final da década de 1990 . 
Em Mato Grosso do Sul, no período compreendido entre 2000 e 2004, foram defendidas 42 dissertações de mestrado em história (Oliveira, 2004). Desses trabalhos, pelo menos 13 abordaram direta ou indiretamente a história de sociedades indígenas que habitam aquele estado atualmente: guarani (kaiowá e ñandeva), kadiwéu, ofayé e terena. Isso equivale a mais de 30\% dos trabalhos defendidos no período em questão. Em outro levantamento mais recente, o historiador Eliazar João da Silva (2007) refere-se às dissertações defendidas no mesmo programa entre 2005 e 2006. Contabilizando mais 17 dissertações, verifica-se que oito delas (ou seja, praticamente metade) estão relacionadas a grupos indígenas.

O destaque dessa produção mais recente fica por conta da incorporação de estudos sobre populações indígenas localizadas em outras unidades da federação, tais como os Bororo (Mato Grosso), os Guarani (Paraná), os Xerente, Xavante, Xakriabá e Akroá (Tocantins, Goiás, Mato Grosso e Minas Gerais). Houve, ainda, certo predomínio de estudos relacionados aos Guarani (subgrupos kaiowá e ñandeva), mas surgiu pelo menos uma investigação a respeito dos Guató, até então não contemplados com pesquisa alguma no referido programa. Deve-se levar em conta, ainda, que o Programa de PósGraduação em História de Mato Grosso do Sul (localizado, a partir de 2006, na recém-inaugurada Universidade Federal da Grande Dourados - UFGD) possui uma linha de pesquisa, única até o momento no país, em história indígena, o que o destaca em relação a outros.

Muitos dos trabalhos sobre populações indígenas realizados em Dourados e em outros centros de pesquisa no país recorrem à utilização de fontes orais. A situação decorre, sobretudo, do fato de os recortes temporais propostos pelos pesquisadores da história indígena se situarem em períodos próximos ao presente. Contudo, não se verificam debates aprofundados acerca de questões teóricas e metodológicas que envolvem o uso dessas fontes e das aproximações e distanciamentos entre os trabalhos de historiadores e antropólogos. Certa confusão se verifica, portanto, nas questões mais diretamente ligadas à metodologia na obtenção de fontes orais. Os diálogos entre história e antropologia, importantes para o desenvolvimento de ambas as áreas do conhecimento, têm-se mostrado um fértil terreno de debates e trocas de experiências. Como afirma a antropóloga Lilia K. M. Schwarcz (2000, p. 11, grifo da autora):

Mais recentemente, alguns trabalhos relevantes têm reaberto o diálogo entre historiadores e antropólogos. Da parte da história parece chamar a 
atenção o uso de conceitos e domínios como a cultura, a estrutura, as noções de símbolo e mito. Isso para não falarmos das tentativas mais imediatas, por parte da Nova História, de retomar a noção de sincronia e combinála com a idéia de longa-duração. Já no interior do campo da antropologia, alguns autores têm procurado introduzir a História em suas análises, revendo antigas práticas que buscaram entender o trabalho empírico como o método privilegiado - e sincrônico -, quase que definidor da disciplina.

As pesquisas em história indígena exigem um minucioso trabalho de interpretação da documentação produzida por viajantes, cronistas, etnógrafos e outros que, ao longo do tempo, conviveram com populações indígenas e sobre elas deixaram registros escritos e iconográficos, dentre outros. Há, ainda, a necessidade de se recorrer a fontes orais, impondo-se a produção de documentação mediante o registro de narrativas, produzidas de acordo com os métodos e procedimentos estabelecidos e consagrados pela história oral.

Apesar da incipiente produção, especialistas brasileiros no assunto já apontam para algumas convergências, em consonância com o que se tem produzido no exterior. Assim, tanto estudiosos nacionais como estrangeiros concordam que nas pesquisas historiográficas realizadas com fontes orais sobre populações indígenas emergem como relevantes certos cuidados metodológicos na leitura e na interpretação das narrativas coletadas e registradas. Esses cuidados remetem, principalmente, às problemáticas das culturas e das relações historiador/narrador e sociedade indígena/sociedade não indígena. ${ }^{4}$

Freitas (2004, p. 187) afirma que, nessas condições:

Fazer História oral é dar voz e dialogar com "o outro”. Fazer História oral indígena, então, é realizar esta tarefa de maneira mais profunda possível, pois se trata de contatar "o outro" no sentido pleno da conceituação cultural.

Mais do que "dar voz", contudo, a história oral permite aos pesquisadores que se ouça e veja o Outro, entendendo a lógica desse Outro situado em contextos culturais diversos. Pode-se dizer, então, que o historiador deve "dar

4 De acordo com o historiador Antônio J. Brand (2002), a pesquisa em história indígena exige do pesquisador uma "expatriação", não apenas para um Outro presente, mas para um Outro culturalmente distinto, situado em distinta tradição cultural. 
ouvidos” ao que o Outro fala, abandonando, assim, uma postura autoritária de tentar ser o porta-voz de quem quer que seja.

Costa $(2002,2005,2008)$, em seus trabalhos com os Nambikuara, propõe a utilização das fontes orais na abordagem etno-histórica do grupo, apoiada no entendimento de que a interdependência entre a prática, a metodologia e a teoria é capaz de produzir conhecimento histórico. Para a autora, as fontes orais carregam em si um importante instrumento de conhecimento, em que os Nambikuara seriam os construtores do cotidiano de sua história, revelando em suas narrativas modos de viver, sentir, experimentar, desejar e pensar os tempos pretérito e presente para, no tempo futuro, sonhar com coisas que podem fazer. Costa ressalva, porém, que seus trabalhos não se estruturam exclusivamente em fontes orais, utilizando-se de fontes manuscritas, iconográficas, cartográficas e bibliográficas, com dimensão de tratamento idêntica à das fontes orais.

Freitas (2002, 2004), em seus trabalhos sobre os Krahô, afirma que a utilização de fontes orais na história indígena exige certo grau de ofícios etnográfico e etnológico, o que obriga muitas vezes o pesquisador à realização de trabalhos de campo. Para a consecução de projetos de história oral com populações indígenas, o autor ressalta que, além da observação antropológica, há de serem enfrentados desafios linguísticos, fazendo-se necessário, em certos casos, um estudo da língua do grupo em questão. Dessa forma, um projeto de pesquisa em história que envolva a utilização de fontes orais no estudo de populações indígenas deve levar em conta uma série de especificidades de cada etnia ou, até mesmo, de cada aldeia.

Ainda de acordo com o historiador:

A temática que a História oral pode abordar vai depender da demanda que cada grupo indígena indicar e sobre a qual cada pesquisador tiver interesse. São questões ligadas ao contato interétnico, etapas de transformações, interferências econômicas e sociais [...]. Afinal, onde o olhar indagador do pesquisador julgar pertinente ir, para descrever, analisar e compreender os fenômenos históricos. (Freitas, 2004, p. 190).

Diferentemente dos olhares de historiadores, tais como Costa e Freitas, Sara Alonso (2001), em seu artigo "Os Tembé e as relações pesquisador-pesquisado", questiona a relação entre antropólogos e sujeitos de pesquisa, a partir de trabalhos de campo realizados entre os Tembé do Guamá, localizados 
na divisa dos estados do Pará e do Maranhão. A autora analisa algumas questões relativas às atribuições culturais dadas à categoria "antropólogo" ou "cientista social” pelos próprios Tembé. As narrativas dos indígenas são utilizadas, então, para desvendar as negociações e representações envolvidas pela presença da pesquisadora entre os sujeitos pesquisados. Mais do que ilustrar, corroborar certas ideias ou auxiliar na compreensão de fenômenos históricos, as falas dos Tembé são consideradas no contexto cultural no qual se realizam e são (re)atualizadas.

\section{Antropologia e fontes orais: o trabalho de campo etnográfico}

Há, certamente, diferenças entre a forma como historiadores e antropólogos percebem a oralidade. Se para o historiador as fontes orais constituem objeto de reflexão e avaliação da veracidade dos dados, para o antropólogo, a forma primeira de aproximação e de obtenção de dados de pesquisa é justamente o trabalho de campo, em que se deve, além de observar, ver e ouvir um grupo de pessoas que darão informações sobre o que se busca. É no informante (ou nativo ${ }^{5}$ ) que a antropologia tem sua principal fonte de conhecimento. Nesse procedimento, ou seja, de buscar nos nativos as versões sobre a vida e a história, a maneira de atribuir significados aos acontecimentos, enfim, de tecer uma narrativa (histórica, mítica, etc.), reside o interesse substancial do antropólogo.

Se a fonte de onde emana, e a partir da qual se constrói o conhecimento antropológico é o nativo, com sua voz, de que maneira a antropologia propõe-se metodologicamente a fazer o trabalho de campo? Bronislaw Malinowski (1980), um dos primeiros a propor um método de trabalho de campo, e do qual todos os antropólogos são herdeiros, afirma enfaticamente que não há como conhecer o Outro, a não ser através de um exercício de distanciamento físico da própria cultura e de uma observação participante, por meio da convivência e compartilhamento de experiências cotidianas do observado. Com essa disposição em observar com grande proximidade um povo ou uma

5 Por nativo se entende alguém a partir de quem se busca o ponto de vista, não devendo ser confundido com a noção mais tradicional de nativo, ou seja, aquele submetido a um regime colonial de opressão. 
cultura, permite-se um movimento interessante, qual seja, o de buscar o ponto de vista do Outro, de entender sua lógica própria.

A respeito disso, Franz Boas $(2004,2005)$, em diversos trabalhos, percebeu que só é possível compreender uma cultura nessa perspectiva. Esse antropólogo colocou-se veementemente contra a explicação evolucionista da história, em que as diferenças culturais seriam explicadas por distintos estágios evolutivos. O particularismo histórico, de acordo com Boas, explicaria a diversidade cultural, combinado com variáveis ambientais e outras. Cada grupo, com sua cultura particular, tem também uma história particular, mas não apenas isso: a singularidade de uma cultura repousa na maneira única de determinado grupo ver o mundo, fazer escolhas, atribuir significados às coisas, etc. Nesse sentido, Émile Durkheim $(1970,1989,1990)$ ajuda a entender essa diversidade cultural e as singularidades, através do conceito de representações coletivas, a partir do qual se verifica a maneira com que uma sociedade percebe o mundo, atribui-lhe significados e como esses significados são sacramentados através do uso e da constante verificação e comprovação de conteúdos.

A esta altura, poderia ser argumentado que história é história e, portanto, a única maneira de ser compreendida seria através dos cânones acadêmicos e dos consagrados materiais para a sua escrita, quais sejam, os documentos escritos. Marshall Sahlins (1990) demonstrou magistralmente, entretanto, que as maneiras de se pensar a história, são situadas e "perspectivadas" pela cultura. Através do estudo do encontro entre havaianos e ingleses, no século XVIII, elaborou a ideia de que a visão de história está muito mais relacionada com a visão de mundo de um grupo do que com uma versão "verdadeira" dos eventos. Isso fica muito evidente com a versão inglesa do encontro com os havaianos e vice-versa.

Desse modo, se a verdade é situada culturalmente, a história oral permite, pois, o contato com essa verdade e com a tradução de uma história produzida por um grupo social. Como Sahlins (1990) ajuda a perceber, há histórias e não uma única história e a tarefa do historiador que trabalha com fontes orais é a de compreender essas versões situadas. O problema aqui parece ser, então, algo que poderia ser chamado de "tradução das versões", ou seja, de que maneira o historiador, através dessa metodologia, deverá controlar a qualidade dos dados e das transcrições. Com essas questões, desvia-se o foco da possibilidade de se crer ou não na "versão nativa", centrando-se, assim, a preocupação do historiador com os métodos e a maneira de escrever. Necessário 
se faz não perder de vista que o "congelamento" de uma narrativa em um texto escrito evidentemente é circunscrito pelos limites dados pelo "aprisionamento" do oral no escrito. Nesse limite, gestos, silêncios, cheiros, cores e sentimentos sutis são praticamente eliminados.

A esse respeito, faz-se coro às palavras da antropóloga Alcida Rita Ramos (1990, p. 128), ao comentar o processo de transformação de falas de indígenas em textos escritos:

Congeladas no papel, essas falas perderam uma gama de elos comunicativos com suas platéias [...] - para em compensação, ganhar a permanência da mensagem registrada, sem aparas, qualificações ou retoques. Na versão escrita não há mais o gesto mediador, o olhar solidário, o silêncio enfático. Nós que as lemos sem tê-las ouvido, temos que nos contentar com essa rendição empobrecida do esforço dialógico dos falantes. [...], embora o gesto esteja invisível, o silêncio inaudível e o olhar perdido, a fala tornada texto adquire uma força própria.

Por outro lado, é o texto escrito a partir da experiência etnográfica que eterniza aquele momento em que a pesquisa foi feita e, muitas vezes, o momento histórico vivido pelo grupo pesquisado. $\mathrm{O}$ exemplo clássico dessa afirmação é o caso mesmo do texto criado por Malinowski (1978) sobre os trobriandeses; enquanto Argonautas do Pacifico Ocidental tornou-se eterno, os trobriandeses, eles mesmos, já são outros, uma vez que já se passaram cerca de cem anos de sua história. Esse presente etnográfico, gravado pela experiência do trabalho de campo, paradoxalmente, torna-se eternizado e atemporal (Clifford, 2008).

Embora tanto a antropologia como a história se beneficiem das fontes orais e busquem nelas um manancial de conhecimentos, certamente a empreitada do antropólogo difere da do historiador. A etnologia baseia-se eminentemente nas fontes orais, mas não prescinde, tampouco, da documentação escrita, da bibliografia, da iconografia e de outras fontes, buscadas, também, pela história, para o desenvolvimento de uma pesquisa. Como explicar, então, duas formas de pesquisar que não se reduzem uma à outra? A observação etnográfica pressupõe uma série de procedimentos metodológicos específicos, dentre os quais o trabalho de campo. A tradição de pesquisa etnográfica na antropologia é uma condição sine qua non, sem a qual o esforço etnográfico se esvazia: a observação de um grupo em seu cotidiano, na tessitura de suas 
ações, na relação entre os indivíduos, no dito e no não dito, nas atividades de sobrevivência, enfim, na observação de aspectos importantes e definidores da singularidade das ações humanas naquela cultura, naquele lugar, naquele momento da pesquisa.

Nada pode, portanto, substituir a pesquisa etnográfica na apreensão do Outro, na busca de traduzir sua cultura em um conjunto de elementos que podem, pelo menos parcialmente, abrir-se para a compreensão da lógica desse Outro, sujeito de reflexão. Assim, a observação do "nativo em carne e osso", parafraseando Malinowski, é o grande ponto de partida para a pesquisa antropológica. Procedimentos de preparação para o campo - registro sonoro e escrito; técnicas de observação e de pesquisa; metodologia - exigem do antropólogo que este compreenda que a fonte de onde emana o conhecimento antropológico é a observação das ações humanas in loco, na busca de apreensão da tessitura do simbólico em uma cultura.

A metodologia da história oral - que observa cuidados de como coletar informações, como entrevistar, confrontar versões, etc. - não pode ser, pois, confundida com o empreendimento etnográfico, embora ambos possam alimentar uma mesma pesquisa. A rigor, a chamada história oral é apenas "uma parte do conjunto de fontes orais e sua manifestação mais conhecida é a entrevista” (Meihy; Holanda, 2007, p. 14). As entrevistas, por sua vez, geram sempre pelo menos um documento material, que é a gravação. Grande parte dos projetos de história oral, contudo, implica a elaboração de um texto escrito, derivado das entrevistas, sendo primordial que se pense tanto no destino das gravações, que devem ser mantidas e disponibilizadas a um público amplo, como no destino do próprio texto escrito. No caso de estudos em história indígena, são as escolhas estabelecidas pelos pesquisadores que definirão em que medida uma disciplina e uma metodologia poderão se complementar.

Há, pelo menos, duas possibilidades de se estudar a história indígena: uma, em que o pesquisador busca a documentação e, através dela, produz uma versão particular do Outro, sem ao menos conhecê-lo. Alguns estudos não poderiam existir de outra forma, especialmente quando se referem a grupos considerados "extintos", como é o caso de A função social da guerra na sociedade tupinambá (Fernandes, 2006). A outra possibilidade é observar os procedimentos metodológicos de trabalho de campo, com a abertura para a versão particular de uma história “étnica” que evidentemente incluirá outros parâmetros, ênfases e modalidades de leitura do tempo, do passado e do 
presente, além do espaço. Tal postura permitirá, inclusive, o entrelaçamento daquilo que se chama de história (algo ocorrido em um passado, com marcos espaciais e temporais claramente situados, de acordo com uma perspectiva não indígena), com narrativas míticas; marcos temporais que podem mesclar-se com a criação do mundo; demiurgos e heróis míticos; animais que falam, têm vontade própria, e inúmeras outras possibilidades de entendimento do mundo.

O que se pretende afirmar é que a empreitada de escrever uma história indígena, por meio de fontes orais, dentre outras, deve supor uma abertura muito grande do pesquisador, além de trabalho de campo com o rigor do método etnográfico de pesquisa. Há que se levar em conta, ainda, o fato de que há grandes chances de se defrontar com outras lógicas de entendimento da história. Um historiador que se aventura pela história indígena deve estar preparado para encontrar (e não desprezar) versões sobre relações interétnicas inesperadas, explicações de mundo e inclusão de elementos aparentemente "estranhos", mas que são determinantes para o curso da história do grupo. Nesse sentido, a ação de xamãs ou de mortos, os locais de moradia de espíritos que podem governar as ações humanas ou a quantidade de chuvas e o estoque de caça podem aparecer nas narrativas como tais elementos.

Acrescentando-se, então, à proposta de Sahlins (1990), de que a concepção de história é situada culturalmente, pode-se propor que as histórias narradas pelos indígenas podem ser percebidas não apenas como a reunião de eventos significativos, mas como um conjunto de elementos que se entrelaçam para compor uma narrativa histórica. Essas narrativas podem ser, então, tecidas pelos eventos significativos em que atores protagonizaram ações, somados a elementos de outros planos que podem inclusive, de um ponto de vista nativo, significar um conjunto de informações que traduzam a história. Na obra de Sahlins (1990) sobre os havaianos, por exemplo, a "confusão" com os ingleses foi possível porque havia, no plano do ritual e do mito, uma disputa entre deuses e humanos.

No campo das relações étnicas, a interpretação da história e dessas mesmas relações pode surpreender. Muitas vezes a visão de sofrimento e de catástrofe é mais dos próprios pesquisadores do que dos grupos que se está estudando. Tentar entender esses argumentos inesperados e aceitá-los pode fazer parte do exercício de se compreender a alteridade e a atribuição particularizada de significados, tanto das ações humanas como dos pensamentos, embora uns e outros não estejam desvinculados, mas estritamente ligados. 
Novamente Sahlins (1990) tem razão, ao propor que se compreenda que homens e mulheres compartilhando uma mesma ação ou um mesmo evento podem pensar e produzir diferentes versões sobre os acontecimentos.

Seja no campo da história ou no da antropologia é possível resolver essas ambiguidades presentes nos discursos aos quais historiadores e/ou antropólogos terão acesso. Aparentemente não seria difícil contemplar as diferentes versões dos eventos e abandonar a busca pelo entendimento de uma "verdade" única. No entanto, é plausível que um historiador se sinta na obrigação de encontrar a "verdade" dos fatos. Essa perspectiva de "verdade" é certamente perigosa para a proposta de entendimento da alteridade, perdendo-se de vista que a verdade é situada culturalmente, quando não, individualmente ou em grupo. Assim, para uma boa história indígena ou uma boa antropologia, o desejável é que se localizem as diversas versões ou interpretações sobre os eventos, e que eles sejam compreendidos de uma maneira em que os atores sociais, produtores dessas interpretações, tenham suas posições situadas.

Nesse sentido, o local de onde alguém fala, o grupo étnico ao qual pertence, a correlação de forças que ele enfrenta são variáveis importantes a serem contempladas em um estudo, seja em um trabalho de campo antropológico ou em uma pesquisa de história indígena com fontes orais. Resumindo, versões diferenciadas, e discursos diferenciados, a respeito de um mesmo evento devem deixar o pesquisador atento; não se deve descartá-las de imediato, como se uma delas fosse mentirosa e houvesse uma única possibilidade de "verdade". Deve-se buscar o entendimento do que estas versões significam e situá-las no campo das relações políticas e culturais dos grupos humanos e dos indivíduos que as produzem. Inúmeros são, portanto, os dilemas de quem passa pelo trabalho de campo, sejam antropólogos, historiadores ou outros pesquisadores.

\section{Considerações finais}

Ao se comparar os trabalhos de historiadores e antropólogos envolvidos com pesquisas que se utilizam de fontes orais, podem-se distinguir algumas afinidades e outras tantas diferenças a respeito de como cada grupo de profissionais aborda os sujeitos. Sobre as afinidades, percebe-se que em se tratando de períodos próximos do presente, os grupos pesquisados geralmente configuram-se como "marginalizados" dentro dos Estados nacionais. Nessa 
situação, as fontes escritas a respeito dos mesmos não existem ou não estão disponíveis de forma satisfatória, o que valida as narrativas orais como fontes cientificamente aceitáveis. Os estudiosos confiam no conhecimento cotidiano, coletado graças à sua presença permanente (no caso da antropologia) ou mediante entrevistas (no caso da história oral). As fontes orais assim obtidas são transcritas, a fim de serem aproveitadas, além de armazenadas.

Mesmo que possa ser dito existir uma situação muito semelhante entre o trabalho do antropólogo que vai a campo e formula perguntas e um pesquisador de história oral ao realizar entrevistas, salienta-se serem diferentes os conteúdos que cada um quer obter com suas indagações. Enquanto antropólogos tratam de captar certos componentes da vida cotidiana como dados etnográficos ou se entendem a si mesmos como ouvintes de uma tradição oral e coletiva, a história oral esforça-se por captar, por intermédio da colaboração de um narrador, uma biografia individual. Essa biografia deve refletir, de forma coerente, a experiência subjetiva de um indivíduo no transcurso de sua vida. Assim, "los contenidos de la tradición oral [captados por antropólogos] tienen un alcance temporal en el pasado mucho mayor que la perspectiva histórica de la Historia Oral, limitada al tiempo de vida del respectivo informante" (Hagen, 1992, p. 108, grifo da autora).

O material que surge, pois, da situação de encontro entre indivíduos, dos quais uns abandonam temporalmente suas atividades acadêmicas para buscar o Outro, possui características distintas para a antropologia e para a história. No trabalho de campo etnográfico, este encontro tem, em geral, uma duração mais longa daquela que ocorre com as entrevistas em história oral, mais limitadas no tempo de execução. Outro aspecto diferenciador é que a transcrição no trabalho antropológico, em geral, é menos exata, mais incompleta e na apresentação do material a individualidade dos narradores é preterida em favor da expressão geral de uma coletividade. Em outras palavras, para muitos antropólogos não é determinado indígena quem fala, mas todo o grupo, através da narrativa de um indivíduo (geralmente mais velho ou de destacada relevância para o grupo). As entrevistas de história oral sustentam-se na força individual de expressão de uma ou mais pessoas, cujos nomes devem ser sempre citados (salvo casos excepcionais) como narradores.

Finalmente, e não menos importante,

en cuanto al trabajo práctico debe designar-se la diferencia que radica en el hecho de que la Historia Oral realiza el proceso concreto de la transcripción 
de una manera a menudo más exacta y cuidadosa que lo que suele ocurrir en las transcripciones antropológicas de textos. (Hagen, 1992, p. 109, grifo da autora).

A análise, ainda que breve, de trabalhos divulgados nos últimos anos envolvendo as pesquisas a respeito de populações indígenas e suas relações com fontes orais, permite entrever uma aproximação e o consequente diálogo que vem ocorrendo entre história e antropologia. Como visto, ambas as áreas do conhecimento podem contribuir para a melhor compreensão do passado, recente ou não, desses agrupamentos sociais. Antropólogos e historiadores têm muito a dialogar, portanto, quando o assunto é o estudo de populações indígenas e suas trajetórias espaciais e temporais no atual território brasileiro. Afinal,

tanto a antropologia como a história possuem suas especificidades na condução de suas pesquisas, mas o movimento contemporâneo de estreitamento da distância entre as duas mostra, por fim, que o encontro é sempre mais rico do que o isolamento. (Agostini, 2000, p. 34).

A possibilidade de se pesquisar história indígena (ou histórias indígenas) está relacionada com um momento político mais recente e não apenas com os avanços das reflexões no campo da história. O olhar que descobre as "minorias", traduzidas no linguajar do politicamente correto como "políticas de inclusão social" (através de regimes de cotas para negros nas universidades; políticas para mulheres, para deficientes, etc.), permite que se amplie o espectro do que é pesquisado. $\mathrm{O}$ avanço nas técnicas de pesquisa, o amadurecimento das reflexões teóricas, a problematização da vocação das ciências em geral (que sempre esteve voltada para as elites e para uma "versão oficial" do mundo) abrem possibilidades para a curiosidade em relação a um Outro, nem sempre tão distante do Eu. Apesar desse incremento no interesse pela história de populações indígenas, há ainda muito a ser pesquisado. No âmbito de pouco mais de 230 grupos indígenas, chega-se à conclusão de que pouco se conhece sobre as especificidades históricas desses grupos e ainda há uma longa caminhada até que se possa dizer que há um bom domínio sobre elas.

Pode-se compreender a importância desses estudos levando-se em conta que a história do Brasil e a história dos indígenas são intimamente entrelaçadas, pois a maior parte das áreas ocupadas por não índios é resultado de 
relações interétnicas eivadas de conflitos (e, não raramente, através do prejuízo impagável à sobrevivência desses grupos, quando não causando mesmo o extermínio físico de muitos deles!). No entanto, ignora-se a presença indígena no presente e no passado da história do país. O estudo das relações interétnicas no Brasil, seja através da história oral, seja através da história registrada através da memória da documentação escrita, deve ser incentivado, uma vez que permitirá que os brasileiros possam compreender melhor a história de índios e não índios. Pesquisadores nacionais precisam, portanto, incorporar em seu horizonte de interesses, os estudos e pesquisas de história indígena.

Para além dos limites do método, é importantíssimo enfatizar que apenas por meio dele pode-se obter boas informações sobre o ponto de vista do pesquisado. Não se trata exatamente de "dar voz" a ele, mas de ouvi-la, uma vez que tentar ver o Outro e entendê-lo é, através de um exercício de autorreflexão, uma experiência radical: a experiência de se deslocar do etnocentrismo e de apreender que há muitas outras soluções possíveis para o viver e outras saídas para a escrita da história vivida. Escrever história, a partir do ponto de vista dos grupos indígenas, enfatiza-se, é também um dever dos historiadores. As vozes indígenas têm sido condenadas ao silêncio, por meio do genocídio sofrido pelos índios, da invisibilização ou de um sistemático processo de se ignorar sua presença pretérita e presente. Agindo dessa forma, ignora-se que a história do Brasil está dolorosamente entrelaçada à história dos índios que aqui viveram e vivem...

\section{Referências}

AGOSTINI, A. J. Jacques Le Goff: por uma nova fronteira entre antropologia e história. In: SCHWARCZ, L. K. M.; GOMES, N. L. (Org.). Antropologia e história: debate em região de fronteira. Belo Horizonte: Autêntica, 2000. p. 33-51.

ALMEIDA, F. A. A. de. Os Kaiowá e Guarani na memória de ex-trabalhadores nos ervais, sob o domínio da Cia. Matte Laranjeira. In: ENCONTRO NACIONAL DE HISTÓRIA ORAL, 9., 2008, São Leopoldo. Caderno de resumos... São Leopoldo: ABHO: Unisinos, 2008. p. 128.

ALONSO, S. Os Tembé e a relação pesquisador-pesquisado. História Oral, São Paulo, n. 4, p. 121-146, jun. 2001.

AMADO, J. História e região: reconhecendo e construindo espaços. In: SILVA, M. A. (Coord.). República em migalhas: história regional e local. São Paulo: Marco Zero, 1990. p. 7-15. 
BOAS, F. A formação da antropologia americana: 1883-1911. Org. George W. Stocking. Trad. Rosaura Maria Cirne Lima Eichenberg. Rio de Janeiro: Contraponto, 2004.

. Antropologia cultural. Trad. Celso Castro. Rio de Janeiro: Jorge Zahar, 2005.

BRAND, A. J. Populaçôes indígenas: algumas considerações metodológicas. Dourados: Programa de Mestrado em História da UFMS, 2002. Mimeografado.

CLIFFORD, J. A experiência etnográfica: antropologia e literatura no século XX. Org. José Reginaldo Santos Gonçalves. Trad. Patrícia Farias. 3. ed. Rio de Janeiro: UFRJ, 2008.

COSTA, A. M. R. F. M. da. Senhores da memória: uma história do Nambiquara do cerrado. Cuiabá: Unicen, 2002. (Tibanaré, 3).

. Yalanewitisu: o espaço nambiquara da memória. História Oral, São Paulo, v. 8, n. 1, p. 61-80, jan./jun. 2005.

. Wanintesu: um construtor do mundo nambiquara. Tese (Doutorado em História)Centro de Filosofia e Ciências Humanas, Universidade Federal de Pernambuco, Recife, 2008.

DURKHEIM, E. Sociologia e filosofia. Trad. J. M. de Toledo Camargo. Rio de Janeiro: Forense, 1970.

. As formas elementares da vida religiosa: o sistema totêmico na Austrália. Trad. Joaquim Pereira Neto. São Paulo: Paulinas, 1989.

. As regras do método sociológico. Trad. Maria Isaura Pereira de Queiroz. 14. ed. São Paulo: Nacional, 1990.

FERNANDES, F. A função social da guerra na sociedade tupinambá. São Paulo: Globo, 2006.

FREITAS, E. B. de. O desafio da etno-história indígena: fala de índio, História do Brasil. In: ENCONTRO NACIONAL DE HISTÓRIA ORAL, 6., 2002, São Paulo. Anais... São Paulo: ABHO: CNPq: USP, 2002. 1 CD-ROM.

. Fala de índio, História do Brasil: o desafio da etno-história indígena. História Oral, São Paulo, n. 7, p. 181-197, jun. 2004.

GIRALDIN, O. Nomes pessoais, tradição oral e identidade: o uso de nomes Panhi (indígena) e Kupẽ (não-indígena) entre os Apinajé. In: ENCONTRO NACIONAL DE HISTÓRIA ORAL, 6., 2002, São Paulo. Anais... São Paulo: ABHO: CNPq: USP, 2002. 1 CD-ROM.

HAGEN, U. História oral indígena. Trad. Oscar Zambrano. Santa Cruz de la Sierra: Apcob, 1992. (Pueblos Indígenas de las Tierras Bajas de Bolívia, 4). 
HOFMANN, A. A. Um novo tempo e um tempo velho: mesmo tempo emaranhado. In: ENCONTRO NACIONAL DE HISTÓRIA ORAL, 9., 2008, São Leopoldo. Caderno de resumos... São Leopoldo: ABHO: Unisinos, 2008. p. 79.

JOSÉ DA SILVA, G. Vozes indígenas na fronteira Brasil-Bolívia: memórias e narrativas Kamba-Chiquitano (segunda metade do século XX). In: ENCONTRO NACIONAL DE HISTÓRIA ORAL, 9., 2008, São Leopoldo. Caderno de resumos... São Leopoldo: ABHO: Unisinos, 2008. p. 78.

LITWINCZIK, V. Memória de famílias do sertão nordestino e o fortalecimento de identidades indígenas. In: ENCONTRO NACIONAL DE HISTÓRIA ORAL, 8., 2006, Rio Branco. Caderno de resumos... Rio Branco: ABHO: Ufac, 2006. p. 166.

LOPES, L. R. Tragetórias indígenas na cidade de Rio Branco (1980-1990). In: ENCONTRO NACIONAL DE HISTÓRIA ORAL, 8., 2006, Rio Branco. Caderno de resumos... Rio Branco: ABHO: Ufac, 2006. p. 93-95.

MACHADO, G. F.; MONTENEGRO, R. D. O uso da imagem como agente que auxilia a História Oral e memória: preservação da cultura dos índios Kapinawá - PE. In: ENCONTRO NACIONAL DE HISTÓRIA ORAL, 8., 2006, Rio Branco. Caderno de resumos... Rio Branco: ABHO: Ufac, 2006. p. 116-117.

MACIEL, L. T. L. As doenças sexualmente transmissíveis e a AIDS no imaginário terena: um estudo de caso entre as mulheres da Aldeia Limão Verde, MS, Brasil. In: ENCONTRO NACIONAL DE HISTÓRIA ORAL, 9., 2008, São Leopoldo. Caderno de resumos... São Leopoldo: ABHO: Unisinos, 2008. p. 123.

MALINOWSKI, B. Argonautas do Pacifico Ocidental: um relato do empreendimento e da aventura dos nativos nos arquipélagos da Nova Guiné Melanésia. Trad. Anton P. Carr; Lígia Aparecida C. Mendonça. 2. ed. São Paulo: Abril Cultural, 1978. (Os Pensadores).

MALINOWSKI, B. Objetivo, método e alcance desta pesquisa. Trad. Olga Lopes da Cruz. In: GUIMARÃES, A. Z. Desvendando máscaras sociais. Rio de Janeiro: Francisco Alves, 1980. p. 39-61.

MEIHY, J. C. S. B.; HOLANDA, F. História oral: como fazer, como pensar. São Paulo: Contexto, 2007.

MIRANDA, J. S. História oral e narrativa entre os Macuxi: reapropriações da memória religiosa a partir das relações de gênero. In: ENCONTRO NACIONAL DE HISTÓRIA ORAL, 7., 2004, Goiânia. Anais... Goiânia: ABHO: UCG: UFG: UEG, 2004. 1 CDROM.

MONTEIRO, J. M. O desafio da história indígena no Brasil. In: LOPES DA SILVA, A.; GRUPIONI, L. D. B. (Org.). A temática indígena na escola: novos subsídios para professores de $1^{\circ}$ e $2^{\circ}$ graus. Brasília: MEC: Mari: Unesco, 1995. p. 221-228. 
OLIVEIRA, J. E. de. Dissertações de mestrado defendidas no Programa de Pós-Graduação em História do Campus de Dourados da UFMS (2000-2004). Fronteiras: Revista de História, Campo Grande, v. 8, n. 15, p. 145-182, jan./jun. 2004.

PORTELA, C. A. Os Karajá de Aruanã-GO e suas diversas falas: identidades e relações de poder em um "espaço" de fronteiras. In: ENCONTRO NACIONAL DE HISTÓRIA ORAL, 7., 2004, Goiânia. Anais... Goiânia: ABHO: UCG: UFG: UEG, 2004. 1 CDROM.

PUHL, J. I. Foi o tempo do chicote um tempo de escravidão? In: ENCONTRO NACIONAL DE HISTÓRIA ORAL, 9., 2008, São Leopoldo. Caderno de resumos... São Leopoldo: ABHO: Unisinos, 2008. p. 144-145.

RAMOS, A. R. Vozes indígenas: o contato vivido e contado. Anuário Antropológico 87. Brasília: Rio de Janeiro, 1990.

RIESTER, J. Textos sagrados de los Guaranies en Bolivia: una cacería en el Izozog. Santa Cruz de la Sierra: Apcob, 1994.

SAHLINS, M. Ilhas de história. Trad. Barbara Sette. Rio de Janeiro: Jorge Zahar, 1990. (Coleção Antropologia Social).

SCHWARCZ, L. K. M. História e antropologia: embates em região de fronteira. In: SCHWARCZ, L. K. M.; GOMES, N. L. (Org.). Antropologia e história: debate em região de fronteira. Belo Horizonte: Autêntica, 2000. p. 11-31.

SILVA, E. Xukuru: a história a partir das memórias, testemunhos e conhecimentos de idosos. In: ENCONTRO NACIONAL DE HISTÓRIA ORAL, 9., 2008, São Leopoldo. Caderno de resumos... São Leopoldo: ABHO: Unisinos, 2008. p. 78-79.

SILVA, E. J. da. Dissertações de mestrado defendidas no Programa de Pós-Graduação em História da Universidade Federal da Grande Dourados (2005-2006). Fronteiras: Revista de História, Dourados, v. 9, n. 16, p. 109-127, jan./jun. 2007.

SILVA, J. A. F.; JOSÉ DA SILVA. História Indígena, Antropologia e fontes orais: algumas questões metodológicas. In: ENCONTRO NACIONAL DE HISTÓRIA ORAL, 8., 2006, Rio Branco. Caderno de resumos... Rio Branco: ABHO: Ufac, 2006. p. 75.

TENEDINI, A.C.Encontros e desencontros: relações interétnicas entre índiose missionários na Prelazia de Diamantino - MT no século XX. In: ENCONTRO NACIONAL DE HISTÓRIA ORAL, 9., 2008, São Leopoldo. Caderno de resumos... São Leopoldo: ABHO: Unisinos, 2008. p. 142.

VON SIMSON, O. de M. Memória, celebração e identidade étnica: uma visão sobre os jogos indígenas e suas potencialidades. In: ENCONTRO NACIONAL DE HISTÓRIA ORAL, 9., 2008, São Leopoldo. Caderno de resumos... São Leopoldo: ABHO: Unisinos, 2008. p. 78. 
Resumo: Os trabalhos com fontes orais relacionados a populações indígenas, no âmbito da história, ainda são escassos, até o presente momento, no Brasil. Por que tão poucos estudos abordam uma temática tão rica, complexa e instigante? Longe de se pretender chegar a uma definitiva resposta a essa pergunta, o objetivo do artigo é ressaltar aspectos teóricos e metodológicos relacionados aos trabalhos de historiadores e antropólogos com as fontes orais. Alguma confusão se verifica quando o assunto é a oralidade, especialmente nas pesquisas realizadas com populações indígenas no Brasil. Deseja-se mostrar que, apesar de semelhanças, há também diferenças que delimitam as áreas de atuação dos pesquisadores da história e da antropologia e não se pode confundir o que cada grupo, com propósitos diversificados (e, às vezes, convergentes), realiza ao investigar grupos étnicos, especificamente indígenas, utilizandose de fontes orais. Múltiplos, portanto, são os desafios para os estudiosos que se aventuram a pesquisar a história dos índios no Brasil. A análise de trabalhos divulgados nos últimos anos, envolvendo pesquisas a respeito das populações nativas e suas relações com fontes orais, permite entrever uma aproximação e o fértil diálogo que pode ocorrer entre história e antropologia. Esse diálogo com o tempo presente, porém, não ocorre sem atritos e, tampouco, sem se verificar que as fronteiras disciplinares, outrora rígidas, são fluidas e permitem complexos e necessários deslocamentos.

Palavras-chave: história, antropologia, fontes orais, métodos, teorias, populações indígenas no Brasil.

History, anthropology and oral sources: theoretical and methodological matters in the dialogue with the present time

Abstract: The works with oral sources related to Indian populations, concerning History, are still rare, until the present time in Brazil. Why very few studies deal with a so rich, complex and instigate thematic? Without the purpose of getting a final response to this question, this paper has as an objective to emphasize works of historians and anthropologists with oral sources. Some confusions are verified when the subject is the oral speech, mainly in the researches carried out with native populations in Brazil. It is intended to show that despite of the similarities, there are differences that delimitate the areas of actuation of the researchers who deal with History and Anthropology and it cannot be confused what each group, with different purposes (and sometimes related), carries out when the investigate ethnic groups, specially Indians, using oral sources. In this way, there are various challenges to the researchers who try to research native History in Brazil. The analyses of works divulgated in the last years, involving oral sources related to the native populations and their relationship with oral sources, permit to imagine an approximation and the interesting dialogue with what can happen between History and Anthropology. This dialogue with the present time, however, does not happen without problems, neither, without the verification that the disciplinary frontiers, strict in other times, are fluids and permit complex and necessary dislocations.

Keywords: history, anthropology, oral sources, methods, theories, native populations in Brazil.

Recebido em 13/04/2010

Aprovado em 31/07/2010 